\title{
Local Criterion for Cleavage Fracture: Structural and Mechanical Approach
}

\author{
B.Z. Margolin and V.A. Shvetsova \\ Central Research Institute of Structural Materials "Prometey", 49 Shpalernaya Str., Saint-Petersburg, \\ Russia
}

\begin{abstract}
On the base of physical-and-mechanical modelling for cleavage microcrack behaviour a new local criterion for cleavage fracture is formulated. Cleavage fracture of pressure vessel steel under various loading history is investigated. It has been experimentally shown that for steels after static prestrain by tension and cyclic prestrain brittle fracture critical stress is described by increasing function of Odqvist's parameter, in the same time plastic precompression results in the significant embrittlement of steel and transition from transcrystalline cleavage fracture to intercrystalline one. Proposed criterion application for predicting fracture toughness dependence on temperature $\mathrm{K}_{\mathrm{IC}}(\mathrm{T})$ and prestrain influence on $\mathrm{K}_{\mathrm{IC}}$ is shown.
\end{abstract}

\section{INTRODUCTION}

At present as a wide-spread formulation of cleavage fracture local criterion one usually uses the equations

$$
\begin{aligned}
& \sigma_{\text {eq }} \geq \sigma_{Y} \\
& \sigma_{l} \geq S_{C},
\end{aligned}
$$

where $\sigma_{\text {eq }}$ - equivalent stress, $\sigma_{Y}$ - the yield stress, $\sigma_{1}$ - the maximum principal stress, $S_{c}$ - critical brittle fracture stress. Condition ( $1 \mathrm{a}$ ) is a necessary condition for brittle fracture and describes cleavage microcrack nucleation. Condition ( $\mathrm{lb}$ ) being a sufficient one determines microcrack propagation condition.

Criterion (1) application gives adequate prediction for critical states of specimens with notchs and cracks in a series of cases. In particular, criterion (1) was successfully used by Wilshaw et al. [1], Knott [2] and Ritchie et al. [3] for prediction of the temperature dependence of $\mathrm{K}_{\mathrm{IC}}(\mathrm{T})$ for low strength steels. It should be noted that criterion (1) is identical to one used in [1-3] in which the nessesary condition (la) was represented in a form $r_{c} \leq t^{p}$ (here $r_{c}$ is a size of process zone near the crack tip, $r^{p}$ is the size of plastic zone near the crack tip).

Nevetheless by using criterion (1) for middle and high strength steels having the low ratio $\mathrm{S}_{\mathrm{C}} / \sigma_{\mathrm{Y}}$ a some contradictions are revealed. For example, the prediction of $\mathrm{K}_{\mathrm{IC}}(\mathrm{T})$ is not adequate to experimental data in the low temperature range. For indicated steels there is a temperature range for which condition ( $\mathrm{lb}$ ) is reached early then condition ( $1 \mathrm{a})$. That's why condition (la) is fulfiled at the higher value of $\mathrm{K}_{\mathrm{IC}}$ with temperature decreasing. To solve this contradiction it is usually assumed that in this temperature range $\mathrm{K}_{\mathrm{IC}}=$ const. 
By tension of smooth and notched specimens it was shown that the maximum principal stress at brittle fracture which interpretated usually as $\mathrm{S}_{\mathrm{C}}$ depends on specimen type (smooth or notched), notch radius and temperature (Beremin [4], Karzov et al. [5]). Model of brittle fracture resolving this contradiction by considering a stochastic nature of cleavage fracture was suggested in [4]. Another approach allowing to resolve these and other disagreements arising by using the local criterion for cleavage fracture (1) was proposed in a series of papers (Karzov et al. [6], Margolin and Shvetsova [7], Margolin et al. [8]).

In the present paper the necessary and sufficient conditions of cleavage fracture criterion are modified on the base of physical-and-mechanical modelling for cleavage microcrack behaviour. New formulation allows to give another interpretation for test results of nothed specimens and to predict adequately dependence $K_{I C}(T)$ and prestrain influence on $K_{I C}$.

\section{MAIN STATEMENTS}

To formulate a local criterion for cleavage fracture the following statements are taken on the base of modern physical ideas about cleavage fracture of bcc-polycrystals.

1. Three processes are to be realised in order that cleavage fracture happens: microcrack nucleation, start and propagation.

2. Brittle fracture in macro-scale may be controlled by each of enumerated processes.

3. Continuous nucleation of cleavage microcracks happens since the condition of nucleation has been fulfiled.

4. Nucleus cleavage microcrack is assumed to be sharp microcrack with the blunting equal to lattice parameter, start of which is defined by Griffith's condition.

5. If $\sigma_{\mathrm{l}} \geq \mathrm{S}_{0}\left(\mathrm{~S}_{0}-\right.$ microcrack start stress) at the moment of sharp microcrack nucleation, this microcrack starts. If $\sigma_{1}<\mathrm{S}_{0}$, nucleus microcrack is blunted due to plastic deformation and transforms into void. Under following plastic deformation such microcrack-void can not be an initiator for brittle fracture: to initiate brittle fracture it is necessary to nucleate a new sharp microcracks.

6. Cleavage microcrack may be arrested by various barriers such as grain boundaries (Hahn et al. [9]), slip bands (Finkel [10]), boundaries of dislocation substructure arising under plastic deformation (Margolin and Shvetsova [7]). Parameter $S_{C}$ is interpretated as stress of microcrack propagation through various barriers.

Physical-and-mechanical modelling for cleavage microcrack behaviour [7] on the base of these statements allows to formulate modified conditions of cleavage microcrack nucleation and propagation. It should be noted that among the enumerated statements the most important ones being different from statements usually used are the second and sixth statements. The second statement, in particular, results in the following consequence: depending on material, stress triaxiality and temperature brittle fracture in macro-scale may be controlled by not only microcrack propagation condition but and microcrack nucleation conditions. The sixth statement allows to explain the increasing of critical brittle fracture stress $\mathrm{S}_{\mathrm{c}}$ by plastic strain increasing [7].

In the case of uniaxial tension of smooth cylindrical specimens the conditions of cleavage microcrack nucleation, start and propagation may be illustrated with the following scheme (Fig.1). At $\mathrm{T} \geq \mathrm{T}^{*}$ brittle fracture of smooth specimens is controlled by microcrack propagation condition, i.e. by $\mathrm{BC}$ curve. The horizontal line on microcrack propagation curve (curve 3 ) is explained by the following way: at $\mathrm{T}<\mathrm{T}^{*}$ plastic strain is absent, therefore critical brittle fracture stress $\mathrm{S}_{\mathrm{C}}$ does not increase and $\mathrm{S}_{\mathrm{C}}=\mathrm{S}_{0}$. At $\mathrm{T}<\mathrm{T}^{*}$ microcrack nucleation process becomes the process controlling fracture in macro-scale, fracture stress increasing with $\mathrm{T}$ decreasing.

Cleavage fracture process at $T \geq T^{*}$ may be represented as follows (Fig.1). After microcrack nucleation the following situations are possible: if $\sigma_{1}<S_{0}$, microcrack start is not realized and microcrack is blunted and is not critical on Griffith's condition by further loading (dot $\mathrm{d}$ in Fig.1). By further plastic deformation a continuous generation of microcracks (dots $e, f, j$ in Fig.1) occurs and by $\sigma_{1} \geq S_{0}$ microcracks begin to propagate in unstable manner. Will or will not this unstable microcrack growth result in fracture in macro-scale - depends on the realization of microcrack propagation condition. Here, one should take into account, that under plastic deformation side 
by side with the increase of deforming stresses $\sigma_{1}$ the increase of cleavage fracture critical stress $\mathrm{S}_{\mathrm{c}}$ as shown below to take place. Till the current value of $\sigma_{1}$ is less than the current value of $S_{\mathrm{C}}$ (i.e. $\left.S_{0} \leq \sigma_{1}<S_{c}\right)$ no fracture in macro-scale occurs: microcracks are propagating unstably up to some barriers such as microstresses and substructure element boundaries and arrested by these barriers (dots $e$ and $f$ in Fig.1). Arrested microcracks are blunted due to plastic strain. At last at $\sigma_{l}=S_{C}$ unstable propagation of microcracks happens and thus fracture of specimen is observed (dot $\mathrm{j}$ ).

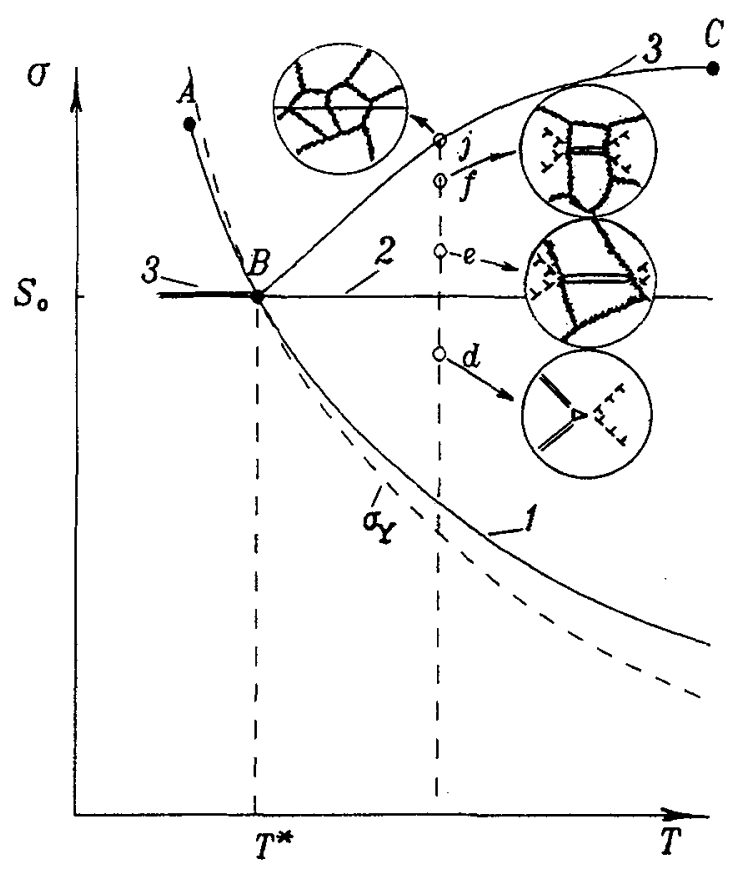

Figure 1: Schematic representation for conditions for microcrack nucleation (carve 1), start (2) and propagation (3) and microcrack interaction with deformation substructure boundaries. Line $A B C$ corresponds to fracture stress at uniaxial tension of smooth cylindrical specimens.

In Fig. 1 the conditions of cleavage microcrack nucleation, start and propagation are shown for the case, when by $\mathrm{T}=\mathrm{T}^{*}$ the minimum value of fracture stress $\sigma_{\min }$ coincides with $\sigma \mathrm{Y}$ (dot $\mathrm{B}$ in Fig. 1). In this point the above mentioned conditions are realized simultaneously. For materials for which by $\mathrm{T}=\mathrm{T}^{*} \sigma_{\min }>\sigma_{\mathrm{Y}}$ the basic laws of cleavage fracture are analogical to considered case.

\section{ANALYSIS OF CLEAVAGE MICROCRACK NUCLEATION CONDITION}

As a criterion of microcrack nucleation, condition ( 1 a) is usually used. At the first sight microcrack nucleation condition (1a) is sufficiently clear physically since there is a series of experimental researchs (for example, Finkel [10], Betechtin et al. [11]), in which microcracks were revealed on the early stages of plastic flow. But nevetheless the question arises, whether any nucleus microcrack is able to initiate cleavage fracture. Analysis of known mechanisms for microcrack nucleation shows that there existed both nucleus microcracks stable to dislocation emission from their tips and microcracks which are blunted at once after nucleation. Only sharp microcracks, i.e. ones being able to unstable growth at the moment of their nucleation may be an initiators for cleavage 
fracture [7]. Experimental investigations [7] showed that nucleation of sharp cleavage microcracks resulting in brittle fracture might take place at large strains. As shown in [7] nucleation condition of sharp microcracks does not coincide with (la) and in common case may be formulated as

$$
\sigma_{1}+\mathrm{m}_{\mathrm{T} \varepsilon}\left(\sigma_{\mathrm{eq}}-\sigma_{0}\right)=\sigma_{\mathrm{d}}
$$

where $\mathrm{m}_{\mathrm{T} \varepsilon}=\mathrm{m}_{0}(\mathrm{~T})\left(\mathrm{c}_{1}+\mathrm{c}_{2} \exp (-\mathrm{A} \chi)\right)^{1 / 2}, \chi=\int \mathrm{d} \varepsilon \mathrm{p}_{\mathrm{eq}}$ - Odquist's parameter, $\mathrm{d} \varepsilon^{\mathrm{p}_{\mathrm{eq}}}$ - equivalent plastic strain increment, $\sigma_{0}$ - friction stress, mo - material parameter depending on temperature, $c_{1}, c_{2}, \mathrm{~A}$ material constant. For $m_{T \varepsilon}$ and $\sigma_{d}$ it is possible to give the following physical interpretation. Depending on mechanism of microcrack nucleation, stress $\sigma_{\mathrm{d}}$ may be the strength of matrix or inclusion or "matrix-inclusion" boundary. Parameter $m_{T_{\varepsilon}}$ characterizes geometry of dislocation pile-up: $m_{\mathrm{T} \varepsilon}$ is the concentration coefficient for local stress in the pile-up tip. To determine parameters $m_{T \varepsilon}$ and $\sigma_{d}$ experimental-calculated procedure based on data about fracture loads for cylindrical tensile notched specimens was developed in [7]. For such specimens the condition of microcrack propagation fulfils earlier than the condition of their nucleation. In this case the brittle fracture of specimens is controlled by the condition (2) only. Parameters $m_{T \varepsilon}$ and $\sigma_{d}$ were determined for pressure vessel $\mathrm{Cr}-\mathrm{Mo}-\mathrm{V}$ steel. These tests showed that sharp microcracks may be nucleated at plastic strains about from 1 to $30 \%$ if temperature increases from $-196^{\circ} \mathrm{C}$ to $-60^{\circ} \mathrm{C}$.

It should be inderlined that as distinct from microcrack nucleation condition (1a) used usually in the proposed condition (2) not only equivalent stress but the maximum principal stress, plastic strain and temperature are taken into account. Exactly this circumstance allows to describe the obtained under rupture of notched specimens dependence of the maximum principal stress on notch radius and temperature.

\section{CRITICAL BRITTLE FRACTURE STRESS ANALYSIS}

Investigations performed in [1-10] allow to draw the following conclusion. $S_{C}$ is low-sensitive to temperature parameter, which defines condition for cleavage microcrack start and propagation through barriers formed at plastic deformation. This condition may be written as

$$
\sigma_{1} \geq \mathrm{S}_{\mathrm{C}}(\chi)
$$

$\mathrm{S}_{\mathrm{C}}(\chi)$ in (3) is monotonous increasing function of accumulated plastic strain only. $\mathrm{S}_{\mathrm{c}}$ increase in deformed material is connected with formation of material deformation substructure, a some elements of which are additional barriers for cleavage microcracks. As such additional barriers there are considered microstresses and boundaries of substructure elements (for example, dislocation cells). As plastic strain increases the cell size decreases and hence the critical length of cleavage microcrack decreases, that leads to increasing $\mathrm{S}_{\mathrm{c}}$. The based on this idea model for $\mathrm{S}_{\mathrm{C}}$ prediction was elaborated in [7]. According to this model $S_{c}(\chi)$ is defined as

$$
\mathrm{S}_{\mathrm{C}}=\left(\mathrm{c}_{1}+\mathrm{c}_{2} \exp (-\mathrm{A} \chi)\right)^{-1 / 2}
$$

The influence of static prestrain by tension and cyclic prestrain on $\mathrm{S}_{\mathrm{C}}$ was experimentally investigated as applied to middle strength $\mathrm{Cr}-\mathrm{Mo}-\mathrm{V}$ steels [7]. Results of tests performed confirmed the functional type of dependence (4) (Fig.2).

At the same time there are experimental data obtained by Allen [12] and Mudry [13] which show that $\mathrm{S}_{\mathrm{C}}$ may decrease after plastic precompression. This phenomenon has been explained not satisfactory.

To investigate this phenomenon tests for determination of $\mathrm{S}_{\mathrm{C}}$ in $\mathrm{Cr}-\mathrm{Mo}-\mathrm{V}$ steel after plastic precompression were performed. Precompression was carried out at temperature $\mathrm{T}=20^{\circ} \mathrm{C}$ up to values of plastic strain $\varepsilon_{\text {com }}=10,20,30$ and $40 \%$. Smooth cylindrical specimens machined from precompressed steel were ruptured by tension at $T=-196^{\circ} \mathrm{C}$. Results of these tests are shown in 
Fig.2. It is seen precompression leads to significant decrease of critical fracture stress $\mathrm{S}_{\mathrm{c}}$. For comparision in Fig. 2 the relation of $S_{c}(\chi)$ for steel in initial state and state after static pretension and cyclic prestrain is represented.

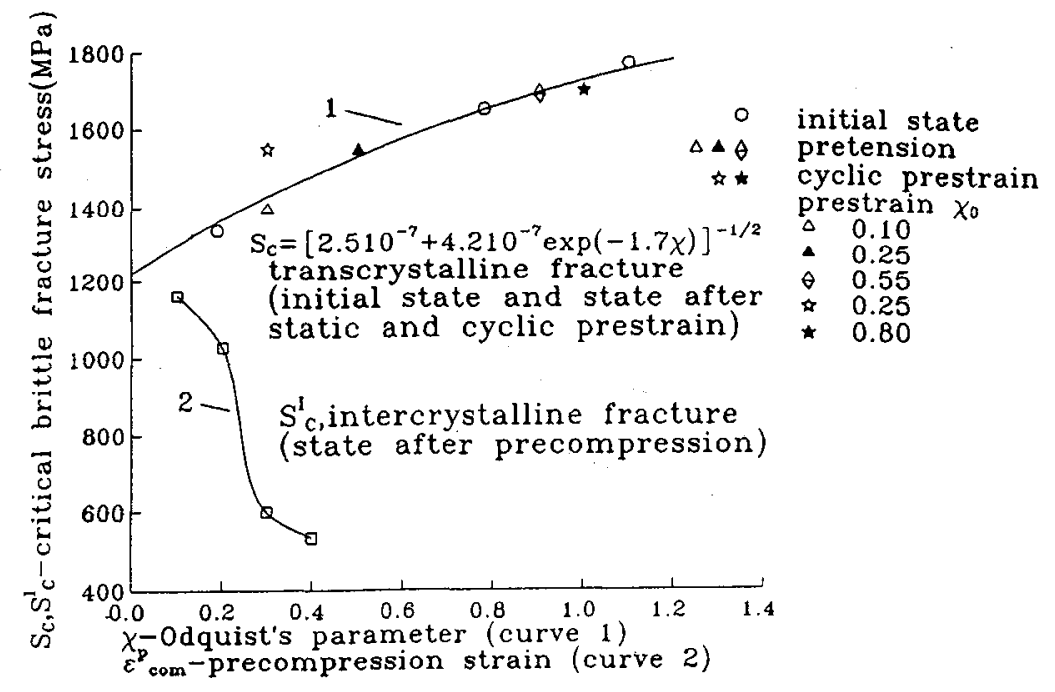

Figure 2: Critical brittle fracture stress vs plastic strain for $\mathrm{Cr}-\mathrm{Mo}-\mathrm{V}$ steel: curve 1 - initial state and state after static pretension and cyclic prestrain; curve 2 - state after precompression.

Fractographic investigation of fracture surfaces of specimens after various plastic prestrain, ruptured by tension at $\mathrm{T}=-196^{\circ} \mathrm{C}$, shows the followings. Brittle fracture mechanism for specimens in initial state and state after static pretension and cyclic prestrain is transrystalline cleavage and microcleavage (Fig.3a). This mechanism is known to be typical for both pearlitic steels and another bcc-metals. Fracture surfaces of specimens after precompression are characterized by intercrystalline fracture regions (Fig.3b). The fraction of such regions in fracture surface increases as $\varepsilon^{p}$ com increase.

Thus, experiments performed show that plastic precompression results in the significant embrittlement of steel and transition from transcrystalline cleavage fracture to intercrystalline one. Such change of brittle fracture mechanisms caused by plastic prestrain is a phenomenon unknown formerly as it may be considered from existing publications. The following physical mechanism of material embrittlement and scheme of transition from transcrystalline to intercrystalline fracture may be proposed.

Microcrack nucleation in structural steels is known to happen on carbides [2], [10]. Analysis performed in (Margolin et al. [14]) shows that nucleation of transcrystalline and intercrystalline microdiscontinuities appear to occur in accordance with the mechanisms represented in Fig.4. Local stress near the tips of dislocation pile-ups shown in Fig.4 a,b is less than the strength of carbide-matrix boundary $\sigma^{c-m}$, but reachs the carbide strength $\sigma^{c}$. For contrary dislocation pile-ups (Fig. 4c) there is a larger local stress (Vladimirov [15]) and fracture of carbide-matrix boundary is possible. In this case nucleus microdiscontinuity is a microvoid. Note, that used here suggestion $\sigma^{\circ}$ $\mathrm{m}>\sigma^{\mathrm{c}}$ is valid as otherwise sharp microcracks on grain boundaries should be nucleated by single dislocation pile-ups and intercrystalline fracture for material in initial state should be observed, that contradicts to experiments (Fig. 3a). So, in steel deformed plastically by tension or compression there are nucleated both sharp transcrystalline microcracks and intercrystalline microvoids. However, evolution of these microdiscontinuities differs under tension and compression: under tension sharp transcrystalline microcracks are blunted and transform into voids, under compression intercrystalline microvoids transform into sharp intercrystalline microcracks. Thus, after pretension in materials there are trans- and intercrystalline microvoid, but 


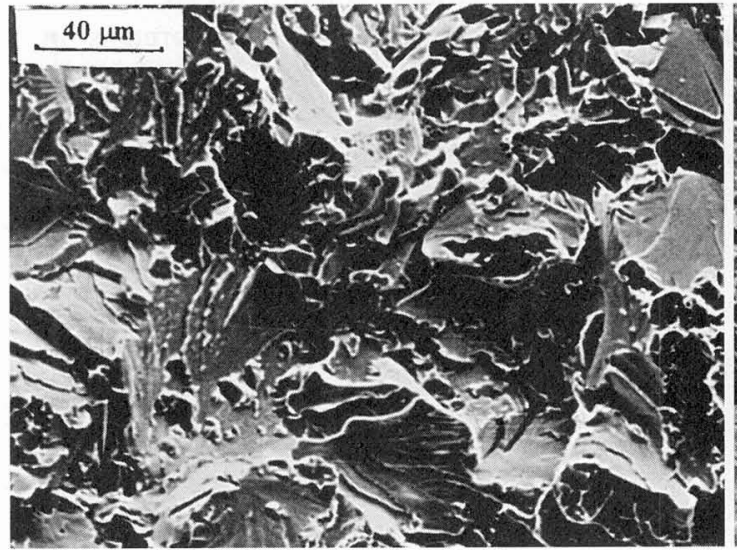

(a)

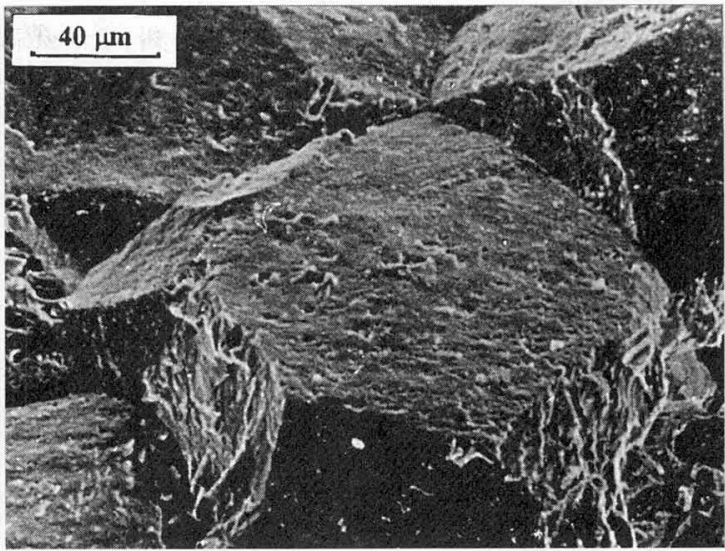

(b)

Figure 3: Fracture surfaces for specimens ruptured by tension at $-196^{\circ} \mathrm{C}$ from $\mathrm{Cr}-\mathrm{Mo}-\mathrm{V}$ steel in initial state (a) and after precompression $\varepsilon \mathrm{p}_{\mathrm{com}}=30 \%$ (b): $\mathrm{a}$ - transcrystalline microcleavage; $\mathrm{b}$ - intercrystalline brittle fracture region.

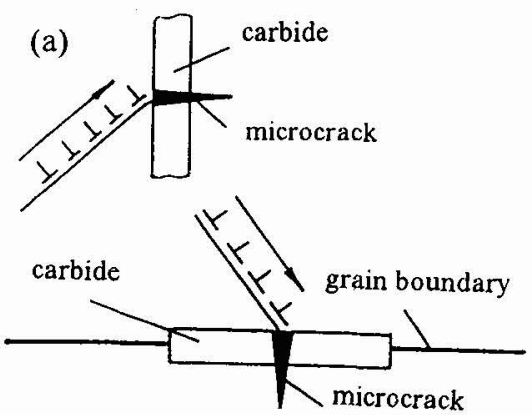

(b)

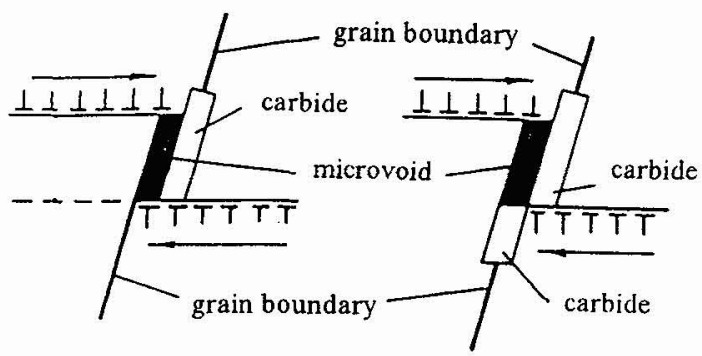

(c)

Figure 4: Mechanisms for nucleation of transcrystalline microcracks on carbides located in grain (a) and on grain boundary (b) and intercrystalline microvoids on carbides located on grain boundaries (c).

after precompression there are trans- and intercrystalline microcracks.

Therefore at the following tension behaviour of material predeformed by tension or compression will be different. To rupture material predeformed by tension it is necessary that a new sharp microcracks are nucleated, start and propagate through material deformation substructure boundaries. New sharp microcracks are transcrystalline as well as ones in material in initial state (Fig. 4 a,b). Deformation substructure formed under pretension leads to additional incresing of $S_{C}$ as compared with material in initial state [7]. 
At the following tension of precompressed material intercrystalline microcracks appear to be an initiators for intercrystalline brittle fracture. Scheme for fracture of material precompressed up to some strain $\varepsilon^{p}$ com and ruptured by tension at different temperatures is shown in Fig.5. At $\mathrm{T}<\mathrm{T}_{0}$ intercrystalline fracture is realized at $\sigma_{1}=\mathrm{S}_{\mathrm{C}}$ and $\sigma_{\mathrm{eq}}<\sigma_{\mathrm{Y}}{ }^{\mathrm{com}}\left(\sigma \mathrm{Y}^{\mathrm{com}}\right.$ - yield stress for precompressed specimen), by this sharp intercrystalline microcracks are not blunted and their propagation leads to intercrystalline fracture of specimen. At $\mathrm{T}>\mathrm{T}_{0}$ fracture is transcrystalline and happens at $\sigma_{1}=\operatorname{Sc}(\chi)$ and $\sigma_{\text {eq }}>\sigma_{Y}{ }^{\mathrm{com}}$, by this intercrystalline microcracks are blunted and transform into voids and transcrystalline cleavage fracture happens from new sharp microcracks nucleated under tension. Temperature of fracture mechanism transition $T_{0}$ and critical stress of intercrystalline fracture $\mathrm{S}^{\mathrm{I}} \mathrm{c}$ depend on $\varepsilon^{\mathrm{p}}$ com. Decreasing dependence $\mathrm{S}_{c}{ }^{\mathrm{I}}\left(\varepsilon^{\mathrm{p}} \mathrm{com}_{c}\right)$ is explained by increase of size of intercrystalline voids nucleated under precompression [15].

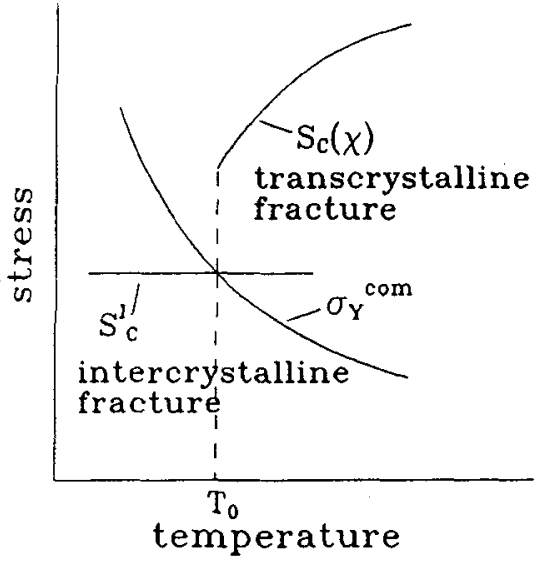

Figure 5: Brittle fracture for precompressed steel (scheme).

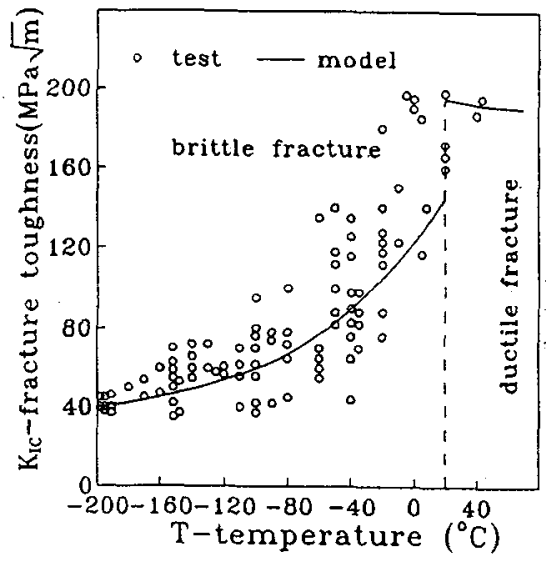

Figure 6: Fracture toughness vs temperature for $\mathrm{Cr}-\mathrm{Mo}-\mathrm{V}$-steel .

\section{FORMULATION OF LOCAL CRITERION FOR CLEAVAGE FRACTURE}

With the consideration of condition for cleavage microcrack nucleation (2), propagation (3) and start $\sigma_{1} \geq S_{0}$ criterion for cleavage trancrystalline fracture may be written as

$$
\begin{aligned}
& \sigma_{1}+\mathrm{m}\left(\sigma_{\mathrm{eq}}-\sigma_{\mathrm{o}}\right) \geq \sigma_{\mathrm{d}} \\
& \sigma_{\mathrm{l}} \geq \mathrm{S}_{0} \\
& \sigma_{\mathrm{l}} \geq \mathrm{S}_{\mathrm{C}}(\chi)
\end{aligned}
$$

In accordance with [7] $\mathrm{S}_{\mathrm{C}} \geq \mathrm{S}_{0}$ at any strain, therefore microcrack start condition may be eliminated from (5).

\section{MODEL FOR FRACTURE TOUGHNESS PREDICTION}

For analytical description of curve $\mathrm{K}_{\mathrm{IC}}(\mathrm{T})$ the following positions are taken [7].

1. The polycrystalline material is considered as an aggregate of unit cells. The unit cell size is equal to the grain size. Stress-strain state on the unit cell is assumed to be homogeneous.

2. At $K_{I}=K_{I C}(T)$ the local fracture criterion (5) must be fulfiled in the unit cell which is the nearest to the crack tip since the fracture condition is fulfiled in it earlier then in unit cells located at a more distance from the crack tip. 
3. Stress-strain state is calculated on the base of the approximated analytical solution represented below.

4. As local fracture criteria the suggested criterion for cleavage fracture (5) and ductile failure criterion [7] are used.

\subsection{Stress-strain state near the crack tip}

In this part the approximate solution [7] for a problem about stress-strain state near the crack tip obtained by using the following statements is represented. equation

1. Elastic-plastic material is considered stress-strain curve for which is approximated by

$$
\sigma=\sigma_{Y}+A_{0}\left(\varepsilon^{p_{e q}}\right)^{\mathrm{n}}
$$

where $\mathrm{A}_{0}$ and $\mathrm{n}$ - material constants.

2. Stress-strain state analysis is performed for the case of plane strain.

3. The crack blunting changing under loading is taken into account.

Consider a crack with the $\delta$ blunting (the blunting radius $\rho=\delta / 2$ ) under loading on mode I. For equivalent stress $\sigma_{\text {eq }}$ and strain $\varepsilon_{\text {eq }}$ near the crack tip the following equation may be written according to (Dixon [16], Karzov and Margolin [17])

$$
\sigma_{\mathrm{eq}} \varepsilon_{\mathrm{eq}}=\sigma_{\mathrm{eq}} \varepsilon_{\mathrm{eq}}^{\mathrm{e}}
$$

where $\sigma^{\mathrm{e}}$ aq and $\varepsilon^{\mathrm{e}_{\mathrm{eq}}}$ - equivalent stress and strain according to elastic solution for problem about stress-strain state near the crack tip; $\sigma_{\text {eq }}$ and $\varepsilon_{\text {eq }}$ - ones according to elastic-plastic solution.

The distribution of stress $\sigma^{\mathrm{e}}$ eq near the tip of crack with the $\delta$ blunting is expressed as [6]

$$
\sigma_{e q}^{e}(r)=\frac{(1-2 \mu) K_{I}}{\sqrt{2 \pi\left(\beta_{1} \delta+r\right)}}
$$

where $r$ - the distance from the crack tip, $\mu$ - Poisson's ratio. Coefficient $\beta_{1}$ is equal to $1 / 16$.

The $\bar{\sigma}_{\text {eq }}^{\mathrm{e}}$ and $\bar{\varepsilon}_{\mathrm{eq}}^{\mathrm{e}}$ values in the unit cell of the size puc are defined as [6]

$$
\begin{gathered}
\bar{\sigma}_{\mathrm{eq}}^{\mathrm{e}} \equiv \frac{1}{\rho_{\mathrm{uc}}} \int_{0}^{\rho_{\mathrm{uc}}} \sigma_{\mathrm{eq}}^{\mathrm{e}}(\mathrm{r}) \mathrm{dr}=2(1-2 \mu) \frac{\mathrm{KI}}{\sqrt{2 \pi}} \frac{1}{\rho_{\mathrm{uc}}}\left(\sqrt{\beta_{1} \delta+\rho_{\mathrm{uc}}}-\sqrt{\beta_{1} \delta}\right) \\
\bar{\varepsilon}_{\mathrm{eq}}^{\mathrm{e}}=\left[\frac{2(1+\mu)}{3 \mathrm{E}}\left(\bar{\sigma}_{\mathrm{eq}}^{\mathrm{e}}\right)\right]
\end{gathered}
$$

Below all stress-strain state parameters are related to the unit cell and in the interest of notation simplicity the lines under corresponding values are omitted. From equations (7), (9) and (10) after a some transformations at $\delta=$ const we obtain

$$
\frac{\mathrm{d} Z}{\mathrm{dJ}}=\beta_{2}\left(\sqrt{\beta_{1} \delta+\rho_{\mathrm{uc}}}-\sqrt{\beta_{1} \delta}\right)^{2},
$$


where $Z=\sigma_{\text {eq }} \varepsilon_{\text {eq }} ; \beta_{2}=\frac{4(1-2 \mu)^{2}}{3 \pi \rho_{\mathrm{uc}}^{2}(1-\mu)} ; J=\left(1-\mu^{2}\right) \mathrm{K}^{2} \mathrm{I} / \mathrm{E}$

Assume eqn (11) to be correct at $\delta$ value changing under loading and take into account the relation $\delta=\beta_{3} \mathrm{~J} / \sigma_{Y}$ (for hardening materials $\beta_{3}=0.25$ (Saka et al., [17])). Then integrating eqn (11) we have

$$
Z=\beta_{2}\left[\alpha J^{2}+\rho_{\mathrm{uc}} \mathrm{J}+\frac{\rho_{\mathrm{uc}}^{2}}{2 \alpha} \ln \frac{\sqrt{\alpha \mathrm{J}}+\sqrt{\alpha \mathrm{J}+\rho_{\mathrm{uc}}}}{\sqrt{\rho_{\mathrm{uc}}}}-\frac{\left(2 \alpha \mathrm{J}+\rho_{\mathrm{uc}}\right)}{2 \sqrt{\alpha}} \sqrt{\mathrm{J}\left(\alpha \mathrm{J}+\rho_{\mathrm{uc}}\right)}\right]
$$

where $\alpha=\beta_{1} \beta_{3} / \sigma Y$.

So, at the known value $\mathrm{Z}$ parameters $\sigma_{\text {eq }}, \varepsilon_{\text {eq }}, \varepsilon^{\mathrm{p}_{\text {eq }}}$ may be determine by using eqn ( 6 ).

At the known $\sigma_{\text {eq }}$ and $\varepsilon_{\text {eq }}$ the stresses on the crack line extent may be found from the following equations obtained on the base of theory for work-hardening plasticity, Mises yield criterion and plane strain condition [16]

$$
\begin{aligned}
& \sigma_{1}=\sigma_{e q} \sqrt{2}\left[(1-q)^{2}+(q-v(1+q))^{2}+(1-v(1+q))^{2}\right]^{-1 / 2} \\
& \sigma_{2}=q \sigma_{1} \\
& \sigma_{3}=v\left(\sigma_{1}+\sigma_{2}\right) \\
& v=\left[0.5-\frac{(1-2 \mu) \sigma_{e q}}{3 E \varepsilon_{e q}}\right] /\left[1+\frac{(1-2 \mu) \sigma_{e q}}{3 E \varepsilon_{e q}}\right]
\end{aligned}
$$

where $\sigma_{1}$-stress perpendicular to the crack line, $\sigma_{2}$ - stress parallel to the crack line, $\sigma_{3}$ - stress out of the plane.

Finite element analysis [17] shown that for a sharp crack $(\delta=0)$ for materials with the hardening modulus varying in a wide range (to $0.05 \mathrm{E}$ ) the parameter $\mathrm{q}$ does not practically depend on the material loading near the crack tip and may be assumed to be equal to 0.65 . For a crack with blunting $\delta \neq 0$ parameter $q$ is defined by the equation [7]

$$
q=\frac{\sigma_{2}}{\sigma_{1}}= \begin{cases}1-\frac{0.85}{0.85+\ln (1+r / \rho)}, & \text { if } r / \rho \leq 3.81 \\ 0.65 & , \text { if } r / \rho \geq 3.81\end{cases}
$$

Equation (14) was deduced by modifying the known equation obtained for blunting crack on the base of slip line theory (Hill [19]).

Thus, to determine the stress-strain state in the nearest to the crack tip unit cell eqns (6), (12), (13) and (14) should be used and in (14) it should be assumed $r=\rho_{u d} / 2, \rho=\beta_{3} J / 2 \sigma Y$.

\subsection{Fracture toughness prediction for pressure vessel steel.}

A calculated curve $\mathrm{K}_{\mathrm{IC}}(\mathrm{T})$ for $\mathrm{Cr}-\mathrm{Mo}-\mathrm{V}$ steel is represented in Fig.6. Performed investigation has shown the followings. At temperature from $-196^{\circ}$ to $20^{\circ} \mathrm{C}$ the brittle fracture is realized according to condition (2), i.e. microcrack nucleation but not propagation is a critical event. Critical brittle fracture stress $S_{C}$ usually considered as a main parameter controlling brittle fracture 
under fracture toughness testing determines the temperature $T_{t r}$ of brittle to ductile transition only, but not a value of $\mathrm{K}_{\mathrm{IC}}$ : the $\mathrm{S}_{\mathrm{C}}$ value is larger the temperature $\mathrm{T}_{\mathrm{tr}}$ is lower. $\mathrm{K}_{\mathrm{IC}}$ value is practically determined by the value of plastic strain at which the condition of sharp cleavage microcrack nucleation (2) is satisfied. At $\mathrm{T}>20^{\circ} \mathrm{C}$ parameter $\mathrm{K}_{\text {IC }}$ is determinated by ductile fracture criterion [7].

For $\mathrm{Cr}-\mathrm{Mo}-\mathrm{V}$ steel after pretension $6 \%\left(\right.$ at $\left.\mathrm{T}=20^{\circ} \mathrm{C}\right)$ fracture toughness $\mathrm{K}^{*}$ IC was calculated. The following results were obtained: at $\mathrm{T}=-196^{\circ} \mathrm{C} \mathrm{K}^{*}{ }_{\mathrm{IC}} \cong 0.75 \mathrm{~K}_{\mathrm{IC}}$, at $\mathrm{T}=-100^{\circ} \mathrm{K}^{*} \mathrm{IC} \cong 0.56 \mathrm{~K}_{\mathrm{IC}}$. Such calculated result which agrees with experimental data (Troshchenko et al. [20]) is highly important since by the use of well-known models (for example, RKR-model [3]) in which traditional formulation of brittle fracture criterion is applied it is difficult to explain the decrease of the lowest shelf of $\mathrm{K}_{\mathrm{IC}}(\mathrm{T})$ curve.

\section{CONCLUSIONS}

1. A new criterion for cleavage transcrystalline fracture has been proposed. Cleavage fracture of notched and cracked specimens from middle and high strength steel has been shown to be controlled by condition for cleavage microcrack nucleation but not propagation.

2. Critical brittle fracture stress $S_{C}$ usually considered as a main parameter controlling brittle fracture under fracture toughness testing determines the temperature $T_{\text {ir }}$ of brittle to ductile transition only, but not a value of $\mathrm{K}_{\mathrm{IC}}$.

3. Prestrain effect on $S_{C}$ under various loading history is experimentally investigated as applied to pressure vessel steel. Plastic precompression has been shown to result in the significant embrittlement of steel and transition from transcrystalline cleavage fracture to intercrystalline one.

\section{REFERENCES}

[1] Wilshaw T.R., Rau C.A. and Tetelman A.S., Engng. Fracture Mech. 1 (1968) 191-211.

[2] Knott J., Fundamentals of Fracture Mechanics (Butterworths, London, England, 1973).

[3] Ritchie R., Knott J. and Rice J., J. Mech. Phys. Solids 21 (1973) 395-410.

[4] Beremin F.M., Met. Trans. 14A (1983) 2277-2287.

[5] Karzov G.P., Margolin B.Z., Pruss A.A. and Shvetsova V.A., Problemy Prochnosti (1989) N11, 9-13 (in Russian).

[6] Karzov G.P., Margolin B.Z. and Shvetsova V.A., Problemy Prochnosti (1989) N 7, 12-21 (in Russian).

[7] Margolin B.Z. and Shvetsova V.A., Problemy Prochnosti (1992) N2, 3-16 (in Russian).

[8] Margolin B.Z., Shvetsova V.A. and Sergeeva M.A., Problemy Prochnosti (1994) N2, 3-21 (in Russian).

[9] Hahn G.T., Averbach B.L., Owen W.S. and Cohen M., "Initiation of cleavage microcracks in polycrystalline iron and steel", Fracture, B.L.Averbach et al. Eds. (MIT Press, New York, 1959) pp. 91-116.

[10] Finkel V.M., Physics of Fracture (Metallurgia, Moscow, 1970) (in Russian).

[11] Betechtin V.I., Vladimirov A.G., Kadomtsev A.I. and Petrov A.I., Problemy Prochnosti (1979) N7, 38-45 (in Russian).

[12] Allen N.P., "Mechanism for brittle fracture of metals", Fracture, B.L.Averbach et al. Eds. (MIT Press, New York, 1959) pp. 121-144.

[13] Mudry F., Nuclear Eng. and Desing 105 (1987) 65-76.

[14] Margolin B.Z., Shvetsova V.A. and Varovin A. Ya., Problemy Prochnosti (1996) N4, 5-18 (in Russian).

[15] Vladimirov V.I., Int. J. Fracture 11 (1975) 359-361.

[16] Dixon I.R., J.Eng. Fract. Mech. 1 (1965) 224-244.

[17] Karzov G.P. and Margolin B.Z., Problemy Prochnosti (1988) N8, 21 -27 (in Russian).

[18] Saka M., Shoji T., Takahashi M. and Abe H., J. Mech. Phys. Solids 30 (1984) 209-224.

[19] Hill R., Mathematical Theory of Plasticity (Clarendon Press, Oxford, England, 1950)

[20] Troshchenko V.T., Pokrovski V.V. and Yasni P.V., Phys.-Chim. Mech. Materialov (1989) N6, 3-12 (in Russian). 